\title{
Agroecologia como puente entre el campo y la ciudad: la construcción de alternativas de comercialización campesina directa en la Ciudad Autónoma de Bueno Aires
}

\author{
Lucas Henrique Pinto ${ }^{1}$
}

RESUMEN: El presente artículo pretende relacionar los desafíos políticos y económicos para la construcción de sistemas agroalimentarios agroecológicos alternativos en circuitos cortos desde la Agricultura Familiar Campesina e Indígena (AFCI) a partir de una experiencia local. Las respuestas productivas a las crisis alimentarias y sanitarias generadas por el sistema agroalimentario corporativo vienen siendo cada vez más visibilizadas desde la implementación de la agroecología por organizaciones campesinas de base. Como estudio de caso presentaremos la experiencia de un proceso concreto de construcción de canales cortos de comercialización agroecológica interinstitucional en la Ciudad Autónoma de Buenos Aires: la Feria Agroecológica De La tierra a tu Mesa. Programa municipal que desde el año de 2019 comercializa de forma directa en 7 parques públicos de la Ciudad Autónoma de Buenos Aires, 20 toneladas mensuales de verduras y frutas, en la modalidad de bolsones agroecológicos, producidos en el cinturón frutihortícola de La Plata, Región Metropolitana de Buenos Aires (RMBA). La experiencia que articula productores campesinos, consumidores urbanos y funcionarios públicos municipales, viene generando tanto alternativa de comercialización directa a los productores agroecológicos como fuente de alimentos sanos y económicos en la ciudad.

Palabras-Claves: Reforma Agraria. Comercialización Directa. Soberanía Alimentaria. Movimientos Campesinos.

\section{AGROECOLOGY AS A BRIDGE BETWEEN THE COUNTRYSIDE AND THE CITY: THE CONSTRUCTION OF DIRECT peasant marketing alternatives in the Autonomous City of Buenos Aires}

Abstract: The article aims to problematize the political and economic challenges for the construction of alternative agroecological food systems in short circuits from the Peasant and Indigenous Family Agriculture (AFCI). The productive responses to the food and health crises generated by the corporate agri-food system have been increasingly visible since the implementation of agroecology by grassroots peasant organizations. As a case study, we will present the experience of a concrete process of construction of short inter-institutional agroecological marketing channels in the Autonomous City of Buenos Aires: the De la tierra a tu Mesa [From the Ground to the Table] Agroecological Fair. Municipal program that since 2019 has directly sold 20 tons of vegetables and fruits per month in 7 public parks of the Autonomous City of Buenos Aires, in the form of agroecological pockets, produced in the fruit and vegetable belt of La Plata, Metropolitan Region of Buenos Aires (RMBA).

${ }^{1}$ Doctor en Ciencias Sociales y Humanas de la Universidad Nacional de Quilmes (UNQ) (2013). Licenciado en Filosofía por la Universidad Federal de São João del Rei (UFSJ) (2008). Fue miembro del Núcleo de Investigaciones en Justicia Ambiental (NINJA-UFSJ) y del Centro de Estudios de la Argentina Rural (UNQ). Becario Posdoctoral en el Centro de Investigaciones Interdisciplinarias en Ciencias y Humanidades de la Universidad Nacional Autónoma de México (CEIICH-UNAM) (20152017). Becario Posdoctoral del CONICET (2015-2018). Actualmente es Becario Posdoctoral (FONCYT/Agencia) y docente en el Programa de Estudios Regionales y Territoriales (PERT) del Instituto de Geografía, Facultad de Filosofía y Letras de la Universidad de Buenos Aires (IIGEO-FFyL, UBA). E-mail: lucashpinto@gmail.com 
The experience that articulates peasant producers, urban consumers and municipal public officials, has been generating both an alternative of direct marketing to agroecological producers and a source of healthy and economical food in the city.

\section{INTRODUCCIÓN}

El presente trabajo pretende problematizar los desafíos políticos y económicos para la construcción de sistemas agroalimentarios agroecológicos alternativos desde la Agricultura Familiar Campesina e Indígena (AFCI), y localmente referenciada. Las respuestas productivas a las crisis alimentarias y sanitarias generadas por el sistema agroalimentario corporativo vienen siendo cada vez más visibilizadas desde la implementación de la agroecología, de forma protagónica- pero no exclusiva- por organizaciones campesinas de base. Parte central de tal proceso es su visibilidad en los grandes centros urbanos que pasan a ser no solo receptivos, sino que cada vez más demandantes de productos de bajo impacto ambiental y de cercanía, con trazabilidad y precios accesibles.

Como estudio de caso presentaremos los desafíos de un proceso concreto de construcción de canales cortos de comercialización agroecológica: la Feria Agroecológica De La tierra a tu Mesa (DLTM). Programa municipal que desde el año de 2019 comercializa de forma directa en 7 parques de la Ciudad Autónoma de Buenos Aires, 20 toneladas mensuales de verduras y frutas, en la modalidad de bolsones agroecológicos, y en transición agroecológica, producidos en el cinturón frutihortícola de La Plata. El programa es una articulación entre organismos públicos de extensión agropecuaria como el Instituto Nacional de Tecnología Agropecuaria (INTA), su Fundación ArgenINTA, Organizaciones campesinas (MTE-Rural y ASOMA), el Gobierno de la Ciudad Autónoma de Buenos Aires (GCABA) y la participación de extensionistas desde el Programa de Estudio Regionales y Territoriales (PERT-UBA) de la Universidad de Buenos Aires (UBA).

\section{Consideraciones Metodológicas}

La presente propuesta -de forma cualitativa- pretende a partir del análisis teórico sobre la agroecología y la problemática ambiental contemporánea, analizar datos cuantitativos de aumento y estabilidad en las ventas de la feria DLTM, analizando la comercialización antes y durante la pandemia del Covid-19, y el incremento en la venta de bolsones de verduras agroecológicas desde marzo de 2020 (POGGI; PINTO, 2021).

También analizaremos las dinámicas de comercialización realizadas en la feria, cantidades y variedades de productos comercializados desde 2019, aumento de los consumidores que buscan productos agroecológicos, mapa y territorialidad de 
las ferias en la Ciudad de Bueno Aires. Analizando cualitativamente las distintas problemáticas surgidas en la constitución de un circuito corto de comercialización local, alternativo y agroecológico. La relación entre productores y consumidores, y el rol del Estado, a partir de sus distintas agencias actuantes, en la construcción del programa de comercialización directa en parques públicos.

Los actores directamente involucrados son el programa Estación Saludable, dependiente de la Dirección General de Desarrollo Saludable, Subsecretaría de Bienestar Ciudadano, Ministerio de Desarrollo Económico y Producción del Gobierno de la Ciudad Autónoma de Buenos Aires. Fundación ArgenINTA, Instituto Nacional de Tecnología Agropecuaria (INTA). Productores rurales campesinos organizados: el Movimiento de Trabajadores Excluidos- Rama rural (MTE-Rural) que ha estado desde el principio de la acción (2019), y la Asociación de Medieros y Afines (ASOMA) posteriormente incorporada en 2020.

Modos de producción alternativos: el debate sobre la AgroECOLOGÍA Y SU RECEPCIÓN EN LA CIUDAD

El modelo productivo agroecológico se viene afirmando cada vez más como una concreta posibilidad de adaptación de la matriz productiva agrícola familiar, frente los retos socioeconómicos y ambientales que se imponen desde la agricultura transgénica industrial, el calentamiento global y su relación directa con la dieta (DELGADO, 2013) y el modo de producción agrícola convencional, principal emisor de gases de efecto invernadero), en el actual régimen alimentario corporativo (MCMICHAEL, 2015).

Con el análisis de los resultados de la presente propuesta, buscaremos identificar las potencialidades y limitaciones de los circuitos cortos para una transición agroecológica y nutricional (a corto y mediano plazo) centrada en la modalidad de comercialización directa de verduras de estación en parques urbanos.

El concepto de soberanía alimentaria gana visibilidad y difusión pública en 1996 -un concepto nacido en la década de 1980 en México (PINTO, 2018), desde La Vía Campesina Internacional (DESMARAIS, 2007) como contrapunto políticosemántico a la idea de seguridad alimentaria (vinculada al modelo de agricultura convencional que defiende el uso de agroquímicos) (CARBALLO, 2011) planteada de forma hegemónica hasta aquel entonces por la FAO (Organización de las Naciones Unidas para la Alimentación y la Agricultura). Nace como concepto en el contexto de las reformas estructurales neoliberales (década de 1980) que ocasionaron la producción intensificada de un régimen alimentario de control corporativo (no más nacional) y de exclusión social a nivel mundial (MCMICHAEL, 2015).

La soberanía alimentaria se muestra desde entonces no sólo como un proyecto 
de cuestionamiento a tal régimen de hambre y marginación, sino también como propuesta de alternativas concretas en múltiples escalas -desde lo doméstico, comunitario y local hasta lo regional y nacional-, representando una respuesta popular-económica y nutricional- al actual calentamiento global y la necesidad de cambiar la agricultura industrializada hacia modelos más sustentables para el medio ambiente y las sociedades, democratizando, efectivamente, la producción y el acceso a los alimentos, planteando la necesidad de una Reforma Agraria Popular e Integral (PINTO, 2016).

El análisis de las prácticas campesinas agroecológicas ${ }^{2}$ demuestra el ejercicio constante en plantear salidas contrahegemónicas frente las crisis alimentarias, sanitarias y climáticas que nos afectan. En este sentido las distintas propuestas de las organizaciones campesinas abogan por una salida colectiva que construya soberanía alimentaria regional y políticas de complementariedad productiva, basadas en un redireccionamiento productivo hacia los alimentos sanos (agroecología), en detrimento de los commodities y del contaminante modelo de los transgénicos y sus impactos en los ecosistemas y en la sociedad.

La percepción global de los efectos ambientales contraproducentes provocados por la producción industrial capitalista (como los monocultivos del sistema agroalimentario corporativo) apareció con fuerza en la arena pública a partir de la Conferencia de Estocolmo en 1972, convocada por las Naciones Unidas (ONU) en base a la propuesta de Suecia, que padecía las externalidades de la "contaminación en el mar Báltico, por lluvias ácidas, por pesticidas y metales pesados encontrados en pescados" (LOPES, 2004, p.19). Estos problemas no eran exclusivos de ese país, sino que eran reflejo de todo el gigantesco aumento productivo vivido por Europa en los años posteriores a la Segunda Guerra Mundial. Desde entonces el tema ambiental pasó a ocupar un papel preponderante en la agenda política de gobiernos, movimientos populares, etc., tal como plantean Lago y Pádua:

Si aceptamos la idea de que el surgimiento y la difusión de una corriente de pensamiento están profundamente vinculados al momento histórico en que ella se manifiesta, podemos encarar la Ecología Social [política] como un caso ejemplar: ella es un fruto típico de nuestra época. Aunque existan raíces de ese tipo de estudio hasta en pensadores de la antigüedad, el hecho es que la percepción de su importancia crucial solamente se torna presente

\footnotetext{
2 "La agroecología surge a partir de la década de 1970 como respuesta teórica, metodológica y práctica a la crisis ecológica y social que la modernización e industrialización alimentaria generan en las zonas rurales. Como práctica, la agroecología propone el diseño y manejo sostenible de los agroecosistemas con criterios ecológicos a través de formas de acción social colectiva y propuestas de desarrollo participativo que impulsan formas de producción y comercialización de alimentos y demás productos agroganaderos que contribuyen a dar respuesta a la actual crisis ecológica y social en las zonas rurales y urbanas" (Sevilla Guzman y Soller, 2009, p. 38).
} 
a partir de la enorme radicalización del impacto destructivo del hombre sobre la naturaleza provocado por el desarrollo del industrialismo. La Ecología Social, por lo tanto, no nació de la cabeza de algunos iluminados, sino de las propias contradicciones reales engendradas por la sociedad urbano-industrial (LAGO; PÁDUA, 1989, p. 24).

Existen desde ya diferentes formas de apropiación y utilización del discurso ambiental. Algunas de ellas, en la búsqueda de la manutención del orden vigente, procuran internalizar las externalidades productivas capitalistas, es decir, mensurar económicamente los desechos de los procesos productivos para con ese dinero supuestamente mitigarlos técnicamente. Otras posturas (ecologismo popular) cuestionan desde una mirada ecológica al sistema capitalista y sus modos de producción (metabolismo social), a los que se los juzga responsables directos de los problemas ambientales, que desde esa perspectiva son conflictos ambientales entre clases.

Por ende, al cuestionar el modelo agroalimentario convencional desde la perspectiva de la soberanía alimentaria y la agroecología se está problematizando los aspectos sociopolíticos, socioambientales y culturales involucrados en los procesos de alimentación (producción, procesamiento, distribución, elaboración y consumo de alimentos). Haciendo hincapié en la constitución soberana de dietas variadamente adecuadas a cada grupo humano específico, basada en su agroecosistema local e historia simbólica y socioeconómica particular. La constitución de una dieta pensada desde la perspectiva de la soberanía alimentaria y agroecología significa llevar en consideración la ubicación geográfica, oferta de biodiversidad local, clima y cuestiones políticas y sanitarias específicas de cada comunidad (PINTO, 2016; 2020).

Los debates sobre las potencialidades y los límites de las prácticas humanas de apropiación de la naturaleza pueden ser entendidos desde ahí sobre el prisma del metabolismo social, por vincular conceptualmente los análisis fisicoquímicos ambientales a los procesos sociales que definen políticamente la forma humana de intervención en los biomas naturales y sus flujos de materia y energía. Por ello, las demandas y las dinámicas del debate ambiental están también vinculadas a los procesos político-económicos por los cuales las sociedades organizan su forma de actuación sobre el ecosistema y sus ciclos metabólicos. Por tales características, la universalizada "crisis ambiental" refleja una fractura de la matriz político-ideológica que orienta las prácticas actuales de intervención humana sobre la naturaleza. Dicha intervención es definida por las acciones hegemónicas desarrolladas por ciertos grupos en la ejecución de sus objetivos e intereses sociopolíticos frente su base natural concreta:

[Los seres humanos por un lado] (...) socializan fracciones o partes de la 
naturaleza, por el otro naturalizan a la sociedad al producir y reproducir sus vínculos con el universo natural. Asimismo, durante este proceso general de metabolismo, se genera una situación de determinación recíproca entre la sociedad y la naturaleza, pues la forma en que los seres humanos se organizan en sociedad determina la forma en que ellos afectan, transforman y se apropian a la naturaleza la cual a su vez condiciona la manera como las sociedades se configuran (TOLEDO; GONZÁLEZ DE MOLINA, 2007, p. 4).

Por lo tanto, la apropiación humana la naturaleza, esencial para nuestra reproducción biológica y social, puede ser, en su versión hegemónica actual, la responsable directa de los desequilibrios ecosistémicos llamados generalmente "problemas ambientales”. Éstos, según Marx, serían “(...) fracturas o [fallas] en la interacción metabólica entre el ser humano y la tierra (...).”3 Estos desequilibrios conforman también los conflictos ambientales, entendidos aquí como las disputas entre los distintos extractos humanos por las formas hegemónicas de interacción/ intervención metabólica con la naturaleza.

Los desequilibrios metabólicos entre las zonas urbanas y rurales serían una expresión concreta de las fracturas metabólicas descriptas originalmente por Marx.

La existencia de territorios cada vez más parasitarios de la producción de alimentos como la ciudad moderna en relación al campo, es una problemática que se ha visto incrementada debido al éxodo rural vivido fuertemente a partir de la Revolución Verde (1960) y la mecanización/industrialización del campo. Dicho modelo propugna una agricultura sin agricultores (luego se justifica así la expulsión de campesinos pobres a los nacientes bolsones de pobreza urbanos) desde donde se puede notar una creciente urbanización mundial asociada al crecimiento industrial y demográfico, procesos que desde la década de 1950 afectan sobremanera a América Latina.

Estos embates industriales y el aumento paulatino de la fractura campo-ciudad, vinculados al nacimiento y la expansión del agronegocio, tienden a disminuir exponencialmente la disponibilidad de tierras cultivadas por habitantes. ${ }^{4}$ En parte

\footnotetext{
3 “[...] esto es, el 'metabolismo social prescripto por las leyes naturales de la vida', a través del 'robo' al suelo de sus elementos constitutivos, exigiendo su 'restauración sistemática'. Esta contradicción se desarrolla a través del crecimiento simultáneo de la industria de larga escala y de la agricultura de larga escala bajo el capitalismo, con aquélla ofreciendo a esta los medios para la exploración intensiva del suelo. Como Libieg, Marx argumentaba que el comercio de larga distancia de los alimentos y de las fibras para el vestuario tornaba el problema de la alienación de los elementos constitutivos del suelo mucho más que una 'fractura irreparable'. Para Marx, eso hacía parte del curso natural del desarrollo del capitalismo" (FOSTER, 2005, p. 220). 4 "Las disponibilidades de tierra cultivada per capita están disminuyendo a medida que crece la población. Ha descendido aproximadamente un 25\% a lo largo de las últimas décadas, pasando de las 0,32 ha de 1979 a las 0,24 ha de 2003 (FAOSTAT, 2003) [FAOSTAT es el anuario de estadísticas de la Organización de las Naciones Unidas para la Alimentación y la Agricultura (FAO)]. A ese fenómeno contribuirá la degradación que muchas de ellas experimentan y van a seguir experimentando de proseguir las mismas prácticas agrícolas" (GONZÁLEZ DE MOLINA, 2011, p. 08).
} 
por esta limitación en la disponibilidad de tierras para la agricultura es lógico pensar que se intente "[...] incrementar la producción con una nueva expansión [...] Las perspectivas refuerzan la idea de que la competencia por la tierra se va a incrementar en los próximos años" (GONZÁLEZ DE MOLINA, 2011, p. 08).

Con el crecimiento demográfico y la gradual concentración de las poblaciones humanas en espacios urbanos (donde casi nunca producen los alimentos que consumen), la cuestión agraria actual se encolumna tras dos grandes objetivos centrales: erradicar la desnutrición y reducir o eliminar los daños ambientales vinculados a las prácticas agrícolas (GONZÁLEZ DE MOLINA, 2011, p. 9). Asimismo, la reforma agraria integral que reivindica las organizaciones campesinas locales e internacionales, por ejemplo, responde, a la cuestión agraria actual que vincula los efectos del avance del capital y su modo de acumulación ampliada en el mundo agrario a problemáticas urbanas de habitación y alimentación.

Esta reforma agraria integral sería, por consiguiente, inherente a la construcción de una nueva relación metabólica sociedad-naturaleza, que modificaría el metabolismo social generador de pobreza entre las sociedades y altamente contaminante a los ecosistemas.

De este modo se reemplazaría el metabolismo social hegemónico en el actual estadio productivo capitalista, que tiene en la privatización y concentración de tierras (que no dejan de ser partes de biomas y ecosistemas) puntos centrales de generación de conflictos ambientales y sociales. ${ }^{5}$

La reforma agraria se torna así una medida esencial en el intento de disminuir la huella ambiental humana (MARTÍNEZ ALIER, 2009) principalmente concentrada en las ciudades ricas del norte global, y a la vez efectuar procesos de justicia social vinculados a las históricas demandas campesinas por la reforma agraria.

Se vuelve a evidencia así, una y otra vez, que más que un problema malthusiano de crecimiento demográfico geométrico y recursos finitos, los problemas y conflictos ambientales, alimentarios y sociales están vinculados a la concentración de estos bienes/recursos comunes esenciales para la vida en pocas manos. Dichos bienes están representados paradigmáticamente en el acceso y la posesión de la tierra y demás bienes comunes presentes en su bioma y su uso sustentable en vistas a la idea de justicia ambiental en la sociedad contemporánea y hacia generaciones futuras. En el intento de generar alternativas tecnológicas y políticas a estos retos

\footnotetext{
5 "Con cerca de aproximadamente la mitad de la población mundial tornándose urbana, muda completamente el sentido de la cuestión agraria. La cuestión agraria hoy, no es más una cuestión específica del campesinado, como hasta recientemente se podría pensar. Al contrario, se torna una cuestión también urbana al insertarse lo urbano en el circuito metabólico de la humanidad con el planeta por las implicaciones impuestas por la necesidad de abastecimiento. La cuestión ambiental exprime mejor de lo que cualquier otra esa imbricación de las contradicciones del capitalismo en su relación con la naturaleza" (PORTO GONÇALVES, 2004, p. 233).
} 
ambientales y sociales que actualmente vivimos, que la agroecología surge como modelo alternativo de interacción metabólico-productiva propuesto desde las organizaciones de pequeños productores que visibilizan a la vez a los procesos de recampesinización (PINTO, 2020) y construcción de un sistemas agroalimentarios alternativos.

La agroecología se basa tanto en la justicia social (reforma agraria) como ambiental, no siendo solamente una forma individual de incrementar los ingresos agropecuarios o de consumir alimentos sanos, sino un modelo productivo que se pretende aplicable, como alternativa, para la sociedad como un todo.

Los debates sobre los procesos de transición agroecológica se encuadran, así, en un panorama más amplio de disputa sociopolítica y productiva entre el modelo hegemónico de agricultura industrializada transgénica de un lado, y el modelo alternativo de producción agroecológica del otro. ${ }^{6}$

Por ende, en estas tensiones derivadas de las dinámicas de concentración y acaparamiento de tierras, se observa un crecimiento sostenido de la conflictividad territorial en América Latina en las últimas décadas, y este proceso genera un terreno fértil para el nacimiento de organizaciones campesinas tanto en los espacios de las economías regionales, como en las zonas periurbanas de los cinturones verdes hortícolas metropolitanos en Argentina. Movimientos originados por componentes variados de migrantes campesino-indígenas y pequeños agricultores familiares, todavía en la tierra, propia o alquilada y poblaciones expulsadas del campo, que se asientan en las zonas periurbanas desde donde siguen reivindicando el acceso a la tierra alquilándola, tomándola o directamente como trabajadores rurales sin tierra (PINTO, 2020).

Si bien hay una variedad de tipos de demandas propias, que van de lo estrictamente sectorial (acceso a la tierra y créditos productivos), hay muchas otras articuladas dentro que buscan dialogar con sectores urbanos: sustentabilidad ambiental, alimentos baratos y de calidad.

El desafío- no exclusivamente corporativo en que se asientan los reclamos de los movimientos campesinos actuales-, en dialogar con los sectores rurales y urbanos se da por la multiplicidad y complejidad de los reclamos, que no se restringen en denunciar las desigualdades del modelo del agronegocio, sino en proponer generar un modelo agroecológico alternativo (PINTO, 2020). En este sentido los reclamos exceden lo puramente corporativo: hablan de la calidad de los alimentos que llegan a las ciudades; las contaminaciones ambientales e intoxicación humana (escuelas,

\footnotetext{
6 "En Argentina, según OXFAM, el 83\% de las Unidades Productivas Agropecuarias detentan solo al 13,3\% del total de tierras productivas. Según otro estudio, la Agricultura Familiar representa a $2 / 3$ de los productores, pero sólo accede al 13,5\% de la superficie de tierra agraria. En 2014, el gobierno argentino, realizó un muestreo de casos de conflicto por la tierra campesina: el resultado arrojó 852 casos abarcando más de 9 millones de hectáreas en conflicto" (MONTÓN, 2019, p. 4).
} 
barrios y pueblos fumigados) generadas por el modelo de agricultura convencional en marcha; la sustentabilidad ambiental del planeta, el calentamiento global, la privatización de las semillas, salud y la reforma agraria integral como forma de descomprimir las ciudades y generar empleo, comercio justo etc. Generando diálogo con los sectores medios y populares urbanos, que se refleja en las acciones llevadas a cabo, como en el estudio de caso que describiremos a seguir.

\section{ESTUdIO DE CASO Y ANÁLISIS DE LOS RESULTADOS}

Las propuestas agroecológicas de la AFCI como parte de la construcción de sistemas agroalimentarios alternativos (SOLLER; PÉREZ, 2013) son respuestas concretas para el desafío de producir alimentos saludables a precios justos en la Argentina actual. La agricultura sostenible que plantean estos sujetos sociales es una síntesis entre los modos de producción tradicionales de las comunidades campesinas (previos a la Revolución Verde) y los procesos de transición ecológica desarrollados en los últimos 40 años, en los marcos de la construcción de sistemas agroalimentarios alternativos, que tienen en la agroecología su matriz filosófica y productiva más difundida, construyendo así una singular propuesta de desarrollo rural agroecológico (PINTO, 2020).

Las experiencia puntal analizada es una inédita articulación entre órganos públicos locales, nacionales y organizaciones campesinas que promueven la comercialización alternativa, procesos que viene creciendo de forma constante en los últimos años. Entre estas propuestas de comercialización directa hay tanto las modalidades de locales (almacenes) propios y ferias, como también canales cortos articulados entre productores y movimientos de consumidores urbanos organizados vía plataforma web.

En general esas experiencias carecen de escala y estabilidad en las ventas (lo que se atenuaría con políticas públicas específicas para el sector, compras públicas para hospitales, escuelas, acceso a la tierra, seguros para cultivos, permisos para realización de ferias etc.).

La experiencia analizada es novedosa- en varios aspectos- en el ámbito de la ciudad de Buenos Aires; tanto por la frecuencia semanal de realización de la feria, como por ser exclusiva a productores agroecológicos, como también por la escala de consumidores que logra atender. Tal experiencia es además una articulación inédita entre las organizaciones campesinas familiares, el INTA y el gobierno la ciudad más rica del país.

De la Tierra a Tu Mesa (DLTM) como se denomina la feria, es una iniciativa de la Fundación ArgenINTA, del Instituto Nacional de Tecnología Agropecuaria (INTA), del Gobierno de la Ciudad Autónoma de Buenos Aires y del Programa de Estudios Regionales y Territoriales de la Universidad de Buenos Aires (PERT- 
UBA), que trabajaron en conjunto para el proyecto asesorando a organizaciones de la Agricultura Familiar del RMBA para que puedan vender sus productos en las ferias realizadas en parques públicos.

DLTM es una política de comercialización de verduras y frutas agroecológicas que producen y comercializan productores familiares campesinos del cordón Frutihortícola de La Plata, asesorados por el INTA, dentro del programa BA Capital Gastronómica.

Desde la Dirección General de Desarrollo Saludable, dependiente de la Subsecretaría de Bienestar Ciudadano y perteneciente al Ministerio de Desarrollo Económico y Producción del Gobierno de la Ciudad Autónoma de Buenos Aires se diagnosticó en el 2018 la necesidad de políticas que facilitaran y ampliaran el acceso directo de las y los vecinos de la ciudad a productos agroecológicos. Surge así la posibilidad de hacerlo en espacios públicos (parques muy concurridos) para incrementar las políticas relacionadas a la alimentación de productos frescos y sanos en Buenos Aires.

Por el lado de los órganos como el INTA y grupos de investigación como el PERT que venimos acompañando a distintos procesos de transición agroecológica de organizaciones de pequeños productores del Cinturón Hortícola Platense (CHP), la comercialización es un tema que siempre inhibe y dificulta al crecimiento de las producciones agroecológicas, como comentado por los productores:

Siempre lo hemos evaluado (hacer producción agroecológica), el tema es que todo eso necesitas... no te digo que capital. Sí capital en personal, digamos. Alguien que salga, haga la venta. Porque el otro factor es la venta, si no la tenés organizada no va a funcionar... porque por ejemplo acá en el mercado no se puede vender...Ahora, si nosotros salimos por ahí puerta en puerta, con una camionetita, como lo hacen algunos en Varela... bueno, ahí podría andar. Pero tenés que buscarle el nicho, tenés que dedicarle tiempo a la venta, para que te sea rentable (Productor Mediano Convencional Propietario) Citado en (BALDINI, 2019, p. 234).

Teniendo en cuenta tal problemática es que DLTM como esquema de comercialización viene a generar una alternativa de comercialización directa para los productores agroecológicos y/o que quieren desarrollar la transición agroecológica y un acceso directo a los consumidores que buscan también alimentos sanos y de cercanías en la ciudad, que a la vez sean económicos.

La idea del proyecto es que los vecinos de la ciudad puedan adquirir bolsones de verduras agroecológicas a un precio más bajo que la oferta en verdulerías, ferias convencionales o supermercados en las 7 Estaciones Saludables ubicadas en 
cada parque. Garantizando también un mercado estable en ventas y precios para sostener e incentivar la producción agroecológica en las organizaciones de pequeños productores participantes.

Creemos que el modelo productivo agroecológico es la vía que debemos seguir para asegurar la soberanía alimentaria y la salud de nuestro pueblo, y lo promovemos a través del aprendizaje y la transmisión de conocimientos y prácticas de campesina/o a campesina/o (MTE-Rural, CARTILLA, 2018, p. 5).

La logística y comercialización están a cargo de los productores y es asesorada por Fundación INTA y PERT-UBA. El programa del gobierno brinda gazebos para la comercialización, también la difusión y promoción de dicha oferta en redes sociales oficiales del gobierno y correos electrónicos. El precio es definido por los productores, teniendo en cuenta siempre una construcción de precio que sea rentable y justa a los productores a la vez que económica para los consumidores en la ciudad.

Objetivos definidos al inicio del programa fueron:

- Promover un mayor consumo de frutas y verduras en los vecinos de la CABA.

- Mejorar el acceso de frutas y verduras a los vecinos de la CABA.

- Promover el consumo de frutas y verduras agroecológicas y de transición.

- Informar a los vecinos de la CABA sobre distintos aspectos de este grupo de alimentos (origen de los productos, circuitos productivos, estacionalidad, formas de preparación, etc.)

- Impulsar la comercialización de pequeños productores y su acercamiento con consumidores.

- Posicionar a las Estaciones Saludables de cada parque como un espacio de promoción y acceso a mayor consumo de frutas y verduras. Se pueden adquirir así bolsones a $\$ 500$ pesos argentinos (mayo de 2021) con $5 \mathrm{~kg}$ con 9 o 10 variedades de una selección de verduras de estación agroecológicas producidas en el CHP. Según la disponibilidad estacional, se ofrecen también bolsones en transición agroecológica de verduras pesadas 6kg (papa, cebolla y calabaza) y bolsones de frutas agroecológicas de $4 \mathrm{~kg}$.

Los dos últimos bolsones son comercializados con productos de otras zonas del país, pero de miembros de las mismas organizaciones, atendiendo tanto a la demanda de los consumidores por mayor variedades en los puestos como aprovechando el circuito de comercialización directa en CABA para generar canales de venta a productores de otras zonas de la provincia de Buenos Aires y del País. La jornada acompaña actividades y eventos de las Estaciones Saludables, como clases de cocina, charlas sobre alimentación saludable y propuestas lúdicas diversas. 
Imagen 1 - Folleto Promocional de la Feria.

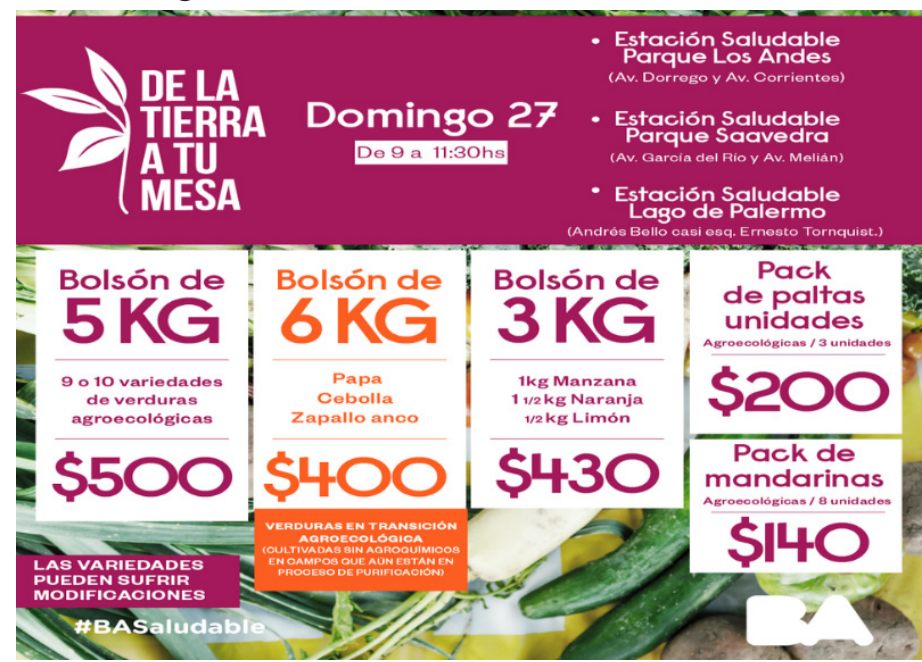

Fuente: Programa De la Tierra a tu Mesa, 2021.

Gráfico 1 - Estructura de precios de bolsones de verdura agroecológica de estación $(5 \mathrm{~kg})$ del MTE-Rural.

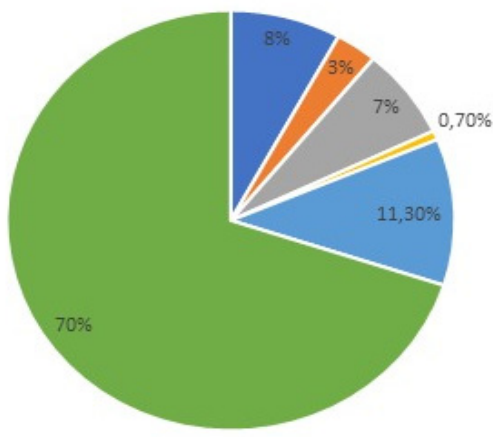

\footnotetext{
- Cooper ativa: trabajadorxs, gastos administrativos, impuestos, etc

- Actividades de formación y desarrollo de parcelas agr oecológicas$$
\text { - Flete }
$$$$
\text { - Bolsa }
$$

- Trabajadoras comer cializadoras pueblo a pueblo y nodos
}

Fuente: MTE-Rural, agosto de 2020. 
Las ventas empezaron en julio de 2019 en los Parques Saavedra y Chacabuco y son semanales (a cada 15 días en cada parque), en 2020 durante la pandemia COVID-19, se sumaron 4 nuevos parques. En 2021 se sumó Rosedal y Saavedra pasó a ser semanal por la alta demanda del barrio. Las ventas se hacen con reservas previas por Internet durante la semana, también hay venta libre en el parque.

La ferias hoy se expandieron a 6 comunas de CABA (ver mapa a seguir): la comuna 4 (Estación Saludable Parque Patricios); la comuna 7 (Estación Saludable Parque Chacabuco); la comuna 12 (Estación Saludable Parque Saavedra); la comuna 15 (Parque Los Andes), comuna 6 (Parque Rivadavia) y comuna 14 (Rosedal y Lagos de Palermo).

Mapa 1- Ciudad Autónoma de Buenos Aires y ferias DLTM.

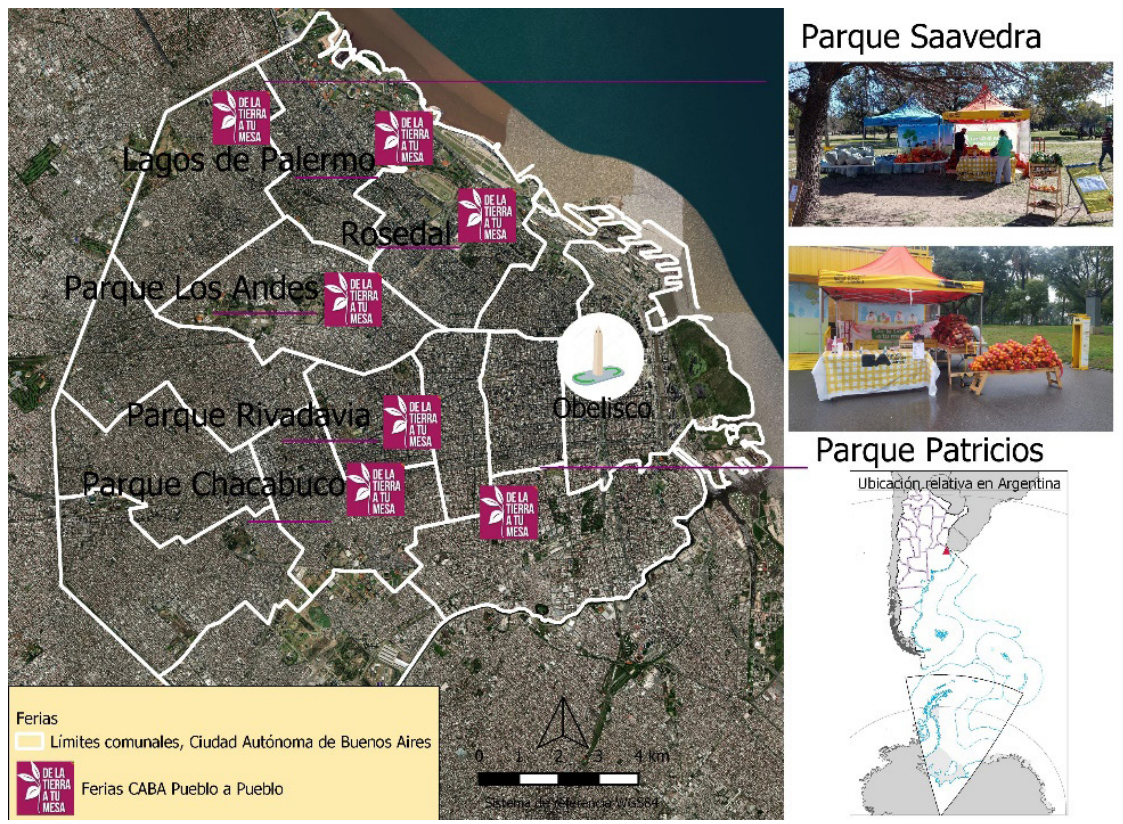

Fuente: Mapa elaborado por la Lic. Julieta Saettone en base a datos obtenidos del autor y de www.ign.com.ar, software Qgis 3.10.10, mayo 2021.

El proyecto se propone en el post pandemia Covid-19 a ampliar a las demás zonas de CABA cubriendo así al total de las comunas que cuentan con Estaciones Saludables, con por lo menos una feria a cada 15 días, fortaleciendo la comercialización de los productores, y una visibilización creciente del proceso de transición agroecológica en la RMBA.

A partir del 20 de marzo de 2020, con el decreto presidencial del Aislamiento 
Social Preventivo y Obligatorio (ASPO), se logro mantener abiertas las ferias aún en los períodos de aislamiento más extremos en la Región metropolitana de Buenos Aires. Logrando el aval de excepcionalidad para el programa por su carácter esencial (alimentos), siendo la única feria de verduras agroecológicas al aire libre que ha funcionado durante todo el período de vigencia de la ASPO. Eso permitió a los productores mantener las ventas, aun durante la cuarentena (ver gráficos $3 \mathrm{y}$ 4 a seguir).

Aumentando el alcance del proyecto con el alza en la demanda de verduras y frutas durante la pandemia, las ferias han visto un fuerte incremento en las ventas. Datos que podemos vislumbrar en los gráficos a seguir:

Gráfico 3 - Total de bolsones vendidos entre agosto 2019 a septiembre de 2020.

\section{Bolsones vendidos por mes (agosto de 2019 a septiembre 2020)}

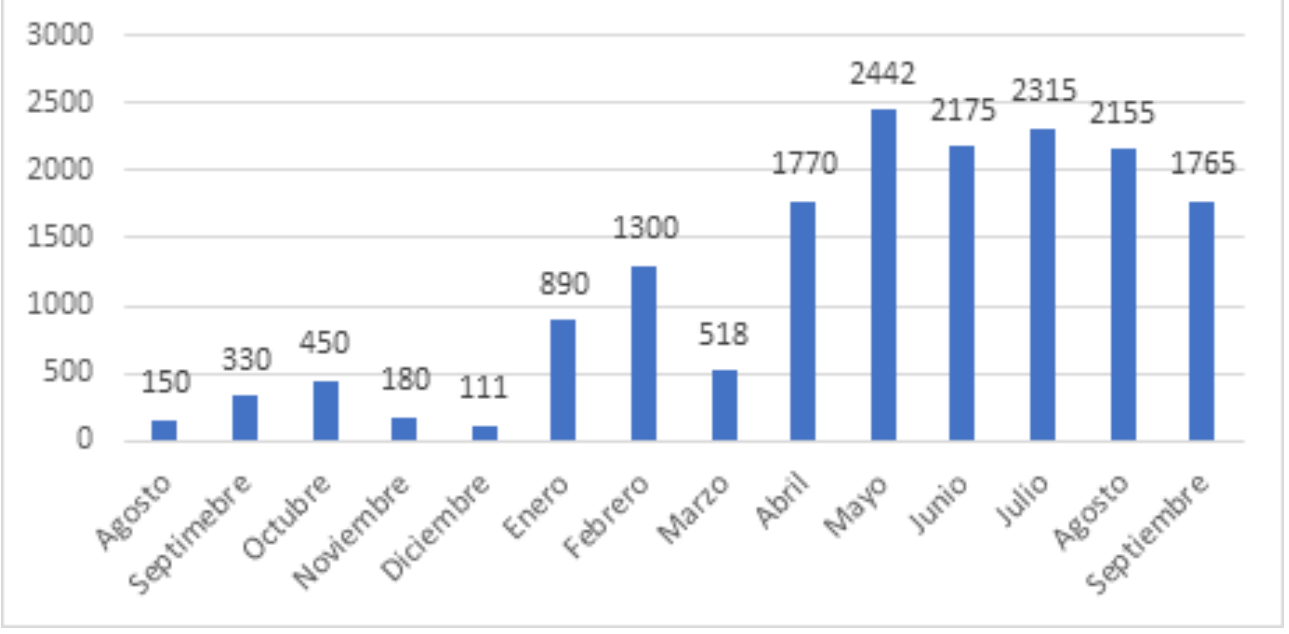

Fuente: Programa De la Tierra a tu Mesa, 2020.

La feria empezó con solo verduras de estación agroecológicas en 2019. En marzo de 2020 se sumaron Bolsones de Verduras de transición: calabaza, papa y cebolla, y Bolsones de frutas agroecológicas. La disminución de marzo de 2020 se debe al inicio de la cuarentena donde la acción estuvo suspendida durante un fin de semana.

E Parque Patricios se inició en febrero de 2020, ya con las tres ofertas de bolsones. La feria en Parque Los Andes empezó en marzo de 2020. En Lagos de Palermo empezó la feria en noviembre de 2020. En el Parque Rosedal, también el barrio de Palermo, la feria empezó en marzo de 2021. La organización a cargo de la venta en 
estos parques es el MTE-Rural.

La feria en Parque Rivadavia empezó en junio de 2020. Es el único parque, hasta el momento, que hace las ventas Asoma.

El total de bolsones vendidos en todos los parques desde julio de 2019 a mayo de 2021 es de 40.168 bolsones. Las ventas vienen en importante incremento durante 2021 cómo se nota en el gráfico a seguir:

Gráfico 4 - Total de bolsones vendidos entre agosto 2019 a mayo de 2021.

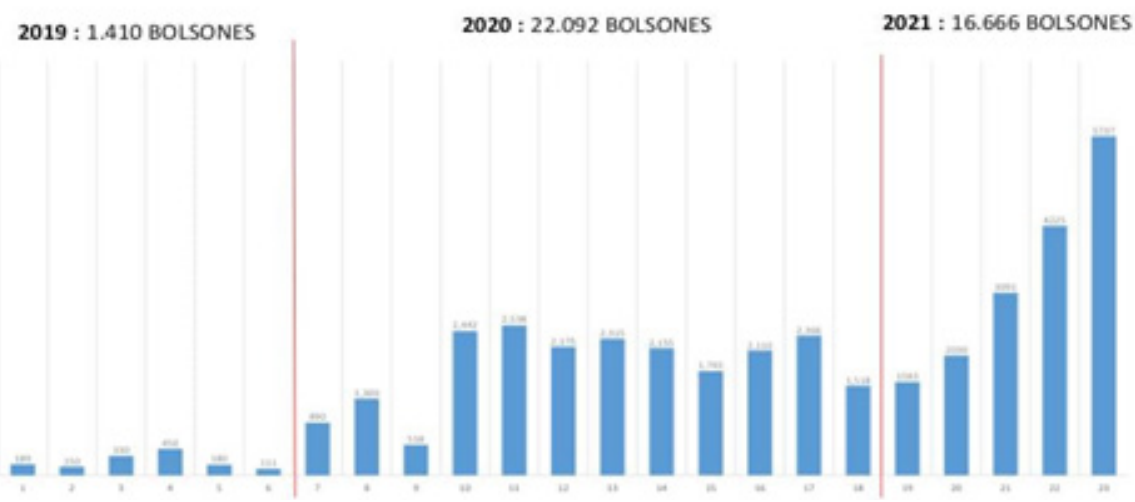

Fuente: Programa De la Tierra a tu Mesa, 2021.

El aumento de las ventas que se puede apreciar en los gráficos ha generado una estabilidad comercial inédita para los y las productoras/es del MTE-Rural que están en el sector de agroecología- el grupo existe desde 2016 y hoy cuenta con 30 familias productoras-. Como comentando por Mabel Vidal una de las referentes del sector en una entrevista sobre el programa DLTM en el marco del aumento en el consumo de productos agroecológicos durante la pandemia, al Diario Clarín:

En La Plata vendíamos 300 bolsones por [por mes]. Ahora que sumamos las ferias en la Ciudad de Buenos Aires [DLTM], son entre 600 y 800, estima Mabel Vidal, militante del MTE-R y productora desde hace 13 años, los últimos dos de verduras agroecológicas. Destaca que antes, por falta de canales de venta, no podían colocar toda la mercadería y terminaban rematándola a un precio muy bajo, como si fueran vegetales convencionales ${ }^{7}$

\footnotetext{
7 "El consumo de nicho que se hizo masivo por la cuarentena: el boom de los bolsones de verdura agroecológica" Consultado el 30/08/20 en: https://www.clarin.com/ciudades/consumo-nicho-hizo-masivo-cuarentena-boom-bolsones-verduragroecologicos_0_y33wzxLiG.html
} 


\section{MTE-RURAL}

El MTE-Rural surgido en la zona del Cinturón frutihortícola de La Plata entre 2014 y 2015, como Movimiento de Pequeños Productores (MPP), está hoy presente en todas regiones del país, en más de 20 provincias, cuenta con 30 mil familias afiliadas. Está vinculado también a otras organizaciones campesinas y urbanas de la economía popular en los marcos de la Unión de Trabajadores de la Economía Popular (UTEP) en Argentina y de La Vía Campesina Internacional. Siendo uno de los destacados representantes de un proceso más amplio de campesinización y recampesinización (Pinto, 2020) en el agro argentino actual, teniendo como importante punto de inflexión y visibilización al Primer Foro por un Programa Agrario Soberano y Popular realizado en mayo de 2019 en la Ciudad de Buenos Aires, por más de 60 organizaciones del sector de la Agricultura Familiar Campesina e Indígena (AFCI).

En el MTE confluimos quienes sostenemos que la Tierra debe ser para quien la trabaja. Hoy más que nunca, frente al avance de una agricultura financiera y especulativa, levantamos la bandera de impulsar una reforma agraria integral y popular en Argentina, que defienda y valorice a las familias que producen alimentos diversificados y de calidad para tas mesas del pueblo argentino, y que considere los derechos políticos y pluriculturales de los pueblos indígenas y de las comunidades campesinas sobre sus territorios (MTE-Rural, 2019, p. 3).

Un año después de la conformación del MTE-Rural y como resultado de las dificultades encontradas por la organización para comercializar su producción de manera directa, sin intermediarios, y de forma justa tanto a los productores como a los consumidores, nace en el año de 2016 Pueblo a Pueblo. Con el objetivo de vincular: "Pueblo productor de alimentos y el Pueblo trabajador de los centros urbanos, con el fin de eliminar la intermediación especulativa que genera enormes aumentos en los precios de los alimentos y no reconoce de forma justa el trabajo de las familias productoras" (COOPERATIVA DE CONSUMO PUEBLO A PUEBLO, 2020).

Al principio la iniciativa comercializaba solamente bolsones de hortalizas de estación de $5 \mathrm{~kg}$ en transición agroecológica, ${ }^{8}$ desde las quintas productivas en el cinturón frutihortícola de la Ciudad de La Plata, provincia de Buenos Aires, hasta la Ciudad Autónoma de Buenos Aires (60 km de distancia).

La propuesta surge de un vínculo directo entre los y las productores del

\footnotetext{
8 "Para la transición agroecológica son necesarios algunos años. Hay necesidad de desintoxicar la tierra y de recuperar e incorporar saberes tradicionales, técnicas y tecnologías, lo que también exige cierto tiempo de aprendizaje y formación. El trabajo humano y las técnicas manuales, por lo menos en parte, precisan sustituir las pesadas máquinas. La posibilidad de generación de renta no siempre es inmediata, sobre todo comparada a los cultivos convencionales" (Schreiner, 2012: 11).
} 
MTE-Rural y organizaciones de consumidores y activistas sociales urbanos, que buscaban tanto alimentos de mejor calidad nutricional y a precios accesibles, como apoyar de forma directa los productores rurales que buscaban la transición desde modos de producción convencionales con agroquímicos a procesos productivos agroecológicos.

Las entregas de verdura se realizaban una vez por mes con la modalidad de reservas previas en formularios digitales, difundidos a través de redes sociales y boca a boca, en un momento (2016) que apenas empezaban a difundirse este tipo de comercialización directa, que vive actualmente un momento de alta difusión pública y crecimiento cuantitativo como ya mencionamos en trabajos previos (PINTO, 2020; POGGI; PINTO 2021).

De forma simultánea Pueblo a Pueblo se organiza en Buenos Aires y en La Plata y se va nacionalizando junto al crecimiento del MTE-Rural. También se fueron sumando otras variedades de productos ofertados, frescos y procesados, de las diferentes cooperativas vinculadas al MTE-Rural y organizaciones de la UTEP.

Dicho proceso de nacionalización se refleja en la presencia de la iniciativa de comercialización en los tres principales centros urbanos del país: Rosario, provincia de Santa Fé, Córdoba Capital y en la Región Metropolitana de Buenos Aires. En la RMBA está presente en la Capital Federal, La Plata, Zona Sur, Zona Norte, Zona oeste y Zona noroeste. También en las provincias de Misiones: Posadas, Puerto Libertad, San Pedro, Eldorado, y en Azul, Junín, Olavarría, y Tandil (interior de la Provincia de Buenos Aires).

En la RMBA la primera regional de Pueblo a Pueblo, y donde se concentra el mayor núcleo poblacional urbano del país, las entregas mensuales realizadas en centros sociales, sindicatos y sedes de organizaciones políticas y barriales (intercaladas con la presencia en distintas ferias como de la Facultad de Agronomía de la UBA), pasaron a partir del 20 de marzo de 2020, con el decreto presidencial del Aislamiento Social Preventivo y Obligatorio (ASPO), a ser semanales y domiciliares (POGGI; PINTO, 2021).

Una de las decisiones fundamentales tomadas por las asambleas de productores fue de no subir el precio de frutas y verduras durante la pandemia en la medida que no fuera realmente necesario para los costos, marcando así una elevada diferencia entre la inflación de frutas y verduras en las redes de comercialización tradicionales, y las ofertas en ferias y circuitos cortos sin intermediarios como Pueblo a Pueblo y DLTM.

Además del precio y calidad de las verduras, las cooperativas de consumo popular suelen tener como valor agregado la politización del consumo de alimentos visibilizando tanto la lucha por la tierra, como el derecho por una alimentación sana y soberana en las ciudades. 
Pueblo a Pueblo como la comercializadora del MTE-R se muestra como un espacio de consumo alternativo en el que la feria DLTM se suma como un canal importante de comercialización del MTE-Rural en CABA, sumado a las entregas domiciliares.

Tanto en la feria DLTM como en las entregas a domicilio el MTE-Rural busca problematizar las forma de producir, la comercialización y el consumo, procurando a partir de tal ejercicio construir el horizonte agroecológico de la soberanía alimentaria. Además, apuestan a generar un consumo responsable que implique acceso a alimentos producidos sin mano de obra esclava, sin contaminar el ambiente ni enfermar a quien los produce ni a quien los consumen, que sean nutricional y culturalmente adecuados, pagando por ellos un precio justo.

\section{ASOMA}

La Asociación de Medieros y Afines (Asoma) es una organización de pequeños productores arrendatarios, y nuclea a cerca de 600 productores en la zona del cinturón hortícola de La Plata. ASOMA se suma a la comercialización en las ferias DLTM casi un año después de su inicio, al principio estuvo solamente el MTE-Rural. Como parte el éxito del programa y aumento sostenible de la demanda en CABA el INTA-AMBA invitó la organización para sumarse a la iniciativa. La producción en transición agroecológica en la ASOMA es reciente empezaron a formarse en el año de 2019. Martín Picchioni, referente de comercialización de ASOMA comenta sobre el programa DLTM:

Si esta propuesta avanza y funciona -agrega Gómez- es un objetivo que ASOMA pueda vender enotros parques de CABA para disponer de nuevos espacios de ventas. Y esta posibilidad de venta tracciona a que estos productores sigan apostatando a la transición de sus sistemas y que cada vez sean más sustentables para la generación de hortalizas más sanos. ${ }^{9}$

La organización está vendiendo sus bolsones en el Parque Rivadavia y comercializa dos tipos de bolsón de verduras, uno de hortalizas de estación de $5 \mathrm{~kg}$ y otro de verduras "pesadas" de 6 kg (papas, cebolla y zapallo) los dos en transición agroecológica.

El proceso de vinculación que propone realizar herramientas de comercialización de las propias organizaciones campesinas en formato de canales cortos directos (comercializadoras, ferias y locales) entre productores y su red de consumidoras y consumidores urbanos, involucra no sólo la venta de productos, sino, además, la

\footnotetext{
9 "El Inta Amba acompaña la venta de alimentos sanos en Estaciones Saludables" Consultado el 18/06/20 en: https://www. noticiasagropecuarias.com/2020/06/18/caba-inta-amba-acompana-la-venta-de-alimentos-sanos-en-estaciones-saludables/ .
} 
realización de talleres y charlas sobre soberanía alimentaria, agroecología, reforma agraria etc.

Como parte de la construcción de Sistemas de Garantía Participativa (SPG), se organizan visitas semestrales a las quintas productivas. Procesos que buscan reforzar los lazos entre productores, consumidores y territorio, generando otros tipos de certificación de la producción agroecológica, que no impacten en una suba de precios de los productos. Lo que ocurre en general con los sellos de certificación orgánica y/o los de denominación de origen geográfica, muy utilizados por el agronegocio verde/orgánico.

\section{ENVASES RETORNABLES}

En los marcos del proyecto DLTM y buscando mejorar la calidad de las verduras en su traslado, desde las quintas productivas hasta la casa de los consumidores, se ha generado para el programa un envase retornable. Sumándose así a las iniciativas, desde del INTA-AMBA, que buscan reemplazar las bolsas de plástico descartable, por una modalidad de entrega que genere menos residuos y permita un mejor traslado de las verduras.

Imagen 2 - Envase Retornable
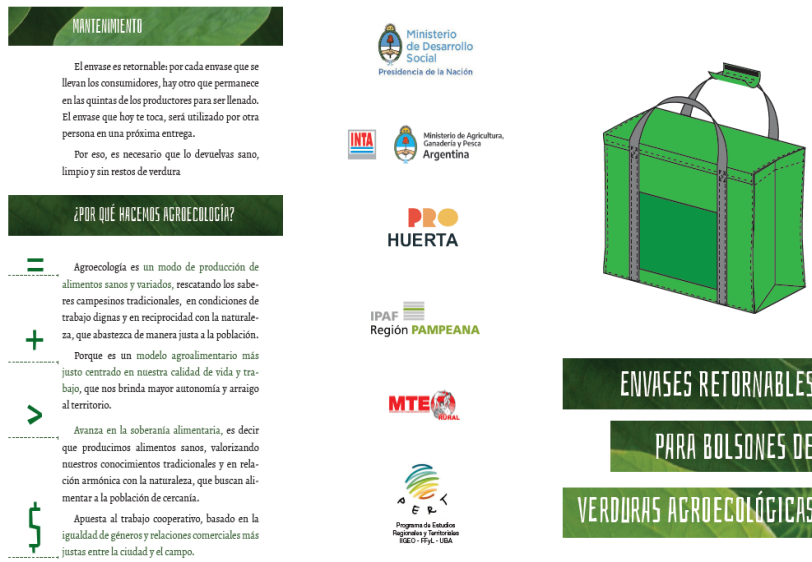

ENUASES RETORNABLES

PHRA BOLSONES DE

VERDURAS AFROECOLÍCICAS

\section{CONSIDERACIONES FINALES}

Las experiencias de comercialización alternativa que vienen creciendo de forma constante en los últimos 5 años, tanto las de comercialización directa (locales propios de productores y ferias), como los canales cortos articulados entre productores y movimientos de consumidores urbanos, son una real alternativa a las cadenas oligopólicas del mercado convencional de alimentos. No obstante, carecen de escala y 
estabilidad en las ventas (lo que se atenuaría con políticas públicas específicas para el sector, compras públicas para hospitales, escuelas, acceso a la tierra, seguros para cultivos etc.) y programas de venta directa como DLTM.

Para lograr el complejo objetivo de la transición agroecológica y la posibilidad de acceso estable y económico a alimentos sin venenos por parte de los sectores populares urbanos, aportando a la constitución de sistemas agroalimentarios locales y alternativo, es fundamental que tanto el Estado (nacional, provincial y local) como instituciones públicas de investigación y extensión, aporten elementos técnicos y teóricos para la construcción de alternativas de comercialización, asesorando y acompañado tanto a productores como a consumidores. Tales iniciativas no carecen de inversión económica significativas, pues se conforman sobre la base de recursos humanos de trabajadores públicos de planta (gobiernos municipales, agencias extensionistas, académicos de universidades públicas), y procesos de transición agroecológicas ya en marcha con recursos propios de las organizaciones de productores. Siendo por lo tanto pasible de ser replicadas en distintas ciudades y localidades no solo de Argentina. El principal aporte por parte del estado local es habilitar la utilización del espacio público para las ventas, además de sus redes sociales oficiales para la difusión y acompañamiento de los consumidores (difusión de recetas para usar con los productos de bolsones y asesoramiento nutricional).

Frente a los diversos desafíos que implica la comercialización las organizaciones van generando una variada gama de modalidades de venta directa, como los bolsones de verdura de estación, ventas por Internet, entregas a domicilio y la apropiación de espacios públicos como ferias y protestas llamadas de "verdurazos".

Las alternativas tecnológicas y políticas que nacen del enfrentamiento a los retos ambientales y sociales que actualmente vivimos, tienen en la agroecología un ejemplo paradigmático de como una propuesta campesina, que nace desde abajo, gana espacio tanto a nivel urbano como legitimidad en el Estado.

El modelo alternativo propuesto desde las organizaciones de pequeños productores que visibilizan a los procesos de construcción de un sistema agroalimentario alternativo y agroecológico en Argentina, vienen ganando apoyo en distintas políticas públicas locales como DLTM y algunos proyectos de ley nacionales. Recientemente el gobierno nacional ha presentado un proyecto de ley para el Fomento a la Agroecología, que plantea entre otras cosas:

1. Creación de un Código de Identificación de las Producciones Agrícolas

2. Promover la certificación participativa de las producciones agroecológicas, de manera de asegurar la certificación en procesos y productos de circulación nacional. 
3. Etiquetado de los productos agroecológicos. La autoridad de aplicación (Ministerio de Agricultura, Ganadería y Pesca) deberá generar los mecanismos de etiquetado para un consumo responsable que garantice el desarrollo de sistemas agroalimentarios sostenibles.

4. Educación agroecológica, tendiente a promover el desarrollo de procesos educativos integrales que orienten a la construcción de una perspectiva agroecológica que alcance a todos los ámbitos de la educación formal y no formal.

5. Creación del Fondo Nacional de Fomento a la Agroecología: Integrado por: a) Las sumas que le asigne el presupuesto general de la Nación; b) Todo otro ingreso que deriva de la gestión de la Autoridad Nacional de Aplicación; c) Las subvenciones, donaciones, legados, aportes y transferencias de otras reparticiones o de personas físicas o jurídicas, organizaciones nacionales e internacionales (Proyecto de Ley para el Fomento a la Agroecología. Presentado en la Cámara de Diputados de la Nación Argentina).

Más allá del potencial masivo y legitimidad que pueda dar a la agroecología su difusión en espacios urbanos y en el ámbito de las políticas públicas locales y nacionales, es importante diferenciar analíticamente la agroecología popular de los movimientos sociales de la "agricultura orgánica" u otros tipos de agriculturas "ecológicas" basadas en el cambio de insumos industriales por fertilizantes y herbicidas orgánicos. Sin embargo, en muchos casos estas agriculturas dichas orgánicas siguen el mismo paradigma y lineamientos productivos del agronegocio: monocultivos, concentración de tierras, productos (alimentos) con alto precio para el consumo suntuoso/sano de las clases medias "ambientalizadas".

La agroecología como parte de las demandas campesinas por reforma agraria y en diálogo con los debates urbanos sobre la sustentabilidad ambiental, no es un nicho de mercado para productores modernos "concientizados" ni una salida exclusiva para consumidores "informados", sino que una alternativa concreta frente las crisis alimentarias, sanitarias y económicas derivadas del continuo colapso socioambiental del régimen alimentario neoliberal hegemónico.

La construcción de canales alternativos de comercialización, enfocados en vender principalmente productores agroecológicos, es parte fundamental del proceso que sostiene y financia con las compras directas a los y las productora(e)s que han decidido reconvertirse en agroecológicos.

Tales circuitos de ventas incentivan así a la transición de cada vez más familias productoras a la agroecología, construyendo circuitos que a su vez generan puestos de trabajo en la ciudad. Abonando así a la construcción de la soberanía alimentaria 
a partir de la existencia concreta de circuitos agroalimentarios diversificados y rentables para el campo y económicos para la ciudad como viene demostrando ser posible la experiencia local de DLTM.

\section{Bibliografía}

BALDINI, Carolina. Territorio en movimiento: las transformaciones territoriales del Cinturón Hortícola Platense en los últimos 30 años. Tesis de doctorado: UNLP, 2020 .

CARBALLO, Carlos. Soberanía alimentaria y producción de alimentos en Argentina. En GORBAN, Miryan K; CARBALLO, Carlos. MERCEDES, Paiva; [et. al.] Seguridad y Soberanía alimentaria. Buenos Aires: Colección Cuadernos. 2011.

DELGADO RAMOS, Gian Carlo. "Cambio climático y la alimentación de las ciudades". Revista Investigación Ambiental. v.5., $\mathrm{N}^{\circ}$ 1. Instituto Nacional de Ecología y Cambio Climático. México, pp. 85-111, 2013.

DESMARAIS, Annette Aurélie. La Vía Campesina. La globalización y el poder del campesinado. Madrid: Editorial Popular, 2007.

GONZÁLEZ DE MOLINA, Manuel. "Agroecológia e Historia Agraria. Una hibridación necesaria." en Estudios Rurales. Publicación del Centro de Estudios de la Argentina Rural. Bernal, vol.1 no 1. pp. 01-29, 2011.

LAGO, Antonio; PÁDUA, José Augusto. O que é Ecologia? São Paulo: Brasiliense, 1989.

LOPES, José Sergio Leite. "Introdução", en LOPES, José Sergio Leite. (Org.) Ambientalização dos conflitos sociais. Participação e controle público da poluição industrial. Rio de Janeiro: RelumeDumará., p.17-38, 2004.

MARTÍNEZ ALIER, Joan. El ecologismo de los pobres: Conflictos ambientales y lenguajes de valores. Barcelona: Icaria, 2009.

McMICHAEL, Philip. Regímenes alimentarios y cuestiones agrarias. México. D.F.: Universidad Autónoma de Zacatecas; Red Internacional de Migración y desarrollo, 2015. 
PINTO, Lucas Henrique. "Soberanía alimentaria, justicia ambiental y resistencia campesina territorial frente a los cambios metabólicos del libre comercio: apuntes teóricos y empíricos desde la experiencia mexicana”. Razón y Palabra. Dossier "Prácticas alimentarias desde una perspectiva sistémica completa". Vol. 20. Núm. 3_94 jul. - Quito- Ecuador, Sept., pp. 517-542, 2016 b.

PINTO, Lucas. Henrique. “Agroecología y recampesinización cualitativa en el agro argentino contemporáneo (2014-2019).” Boletín De Estudios Geográficos, (113), 2020.

POGGI, Marina; PINTO, Lucas Henrique. "Visibilización de la agroecología periurbana durante la pandemia: el uso de las redes sociales para la militancia del plato". Revista TOMO: UFS. No36, 2021.

SARANDÓN, Santiago. J.; MARASAS, Mariana. E. "Breve historia de la agroecología en la Argentina: orígenes, evolución y perspectivas futuras."Agroecología, v. 10, n.2, p 93-102, 2017.

SAUER, Sérgio e BALESTRO, Moisés. (orgs.)Agroecologia e os desafios da transição agroecologica. São Paulo: Expressão Popular, 2013.

SCHREINER, Davi F. “Territorialidades em disputa. Os assentamentos, o MST e a luta coletiva.” Mendoza: Actas de las 3ras Jornadas Internacionales de Problemas Latinoamericanos: Movimientos Sociales, Estados y partidos Políticos en América Latina: (re) configuraciones institucionales, experiencias de organización y resistencia. (CD-ROM), 2012.

SEVILLA GUZMÁN, Eduardo; SOLER MONTIEL, Marta. "Del desarrollo rural a la agroecología. Hacia un cambio de paradigma”. Documentación Social, Núm. $155,2009$.

SOLLER MONTIEL, Marta; PÉREZ NEIRA, David. “Canales cortos de comercialización alimentaria en la construcción de sistemas agroalimentarios alternativos." en CUÉLLAR, Mamen., CALLE Ángel y GALLAR, David (eds.) Procesos hacia la soberanía alimentaria: Perspectivas y prácticas desde la agroecología política. Barcelona: Icaria. p.63-80, 2013.

TOLEDO, Víctor.; MOLINA, Manuel Gonzáles de., “El metabolismo social: las 
relaciones entre la sociedad y la naturaleza." en Francisco Garrido, Manuel. González de Molina, (eds), El paradigma ecológico en las ciencias sociales. Barcelona: Icaria., p.01-25, 2007.

TOLEDO, Víctor Manuel. "La agroecología en Latinoamérica: tres revoluciones, una misma transformación.” Agroecología, Núm. 6, 2012. 